\title{
Solar cell development research: a Sri Lankan perspective
}

Non availability of energy resources or restricted access to energy resources is a major crisis in any country. This problem is further aggravated by the massive increase in global energy demand due to industrial development as well as population growth. Consequently, a very high competition is generated among countries to acquire the limited energy resources to maintain a continuous energy supply. Global energy resources such as oil, coal and natural gas are causing many problems in connection with the cost, environmental issues and political issues. Burning fossil fuels while satisfying $81 \%$ of the global energy demand contributes to $69 \%$ of the global greenhouse gas emissions. This global environmental issue of the emission of greenhouse gases is considered as a main threat to the very existence of life on earth. Energy supply through non carbon energy resources is considered as the most promising solution to the present energy problem and renewable energy sources are in the forefront in this respect (Boyle, 2012). Considering the economic and environmental benefits, the world community has already launched various programmes to replace fossil fuels with renewable energy resources. Energy supply through renewable sources has been a mere $16 \%$ globally, and at national levels at least 30 nations around the world already have renewable energy contributing to more than $20 \%$ of their energy supply.

Research and development of solar energy converting devices for applications in energy sector has been in existence for many decades. Solar heating, solar drying, solar thermo-electricity generation and photovoltaic solar energy conversion are examples for available technologies for harnessing solar energy. Further, chemical storage of solar energy, for example, hydrogen production by water splitting using sun light, is an active research area. Among all, photovoltaic solar cell research and development has a prominent place. As a result, semiconductor silicon based solar cell devices are at the forefront today, while the emerging technology is on the development of thin film solar cells using other semiconductor materials.
In general, solar researchers can be divided into two categories in their pursuit of cheaper solar energy devices. Some have sought solar cells that can be made with a very low cost but have the downside of being relatively inefficient. Other researchers have focused on developing very high efficiency cells, even if they require more expensive manufacturing techniques. There is a quest for new solar energy materials that can produce highly efficient but low cost solar cells. The real challenge to solar cell technology is the competition with fossil fuels because the cost of production of solar cell devices is still higher than fossil fuels. However, with the depletion of available reserves the cost of production of fossil fuels will be comparable with solar cells in the future. Yet the damage done to the environment by using fossil fuels will be immense and irrecoverable. This reality has been well understood by the world community and the research effort in developing low cost solar energy converting devices is tremendous and the number of research programmes conducted worldwide is extremely large (Hamakawa, 2004).

Majority of the universities and research institutes worldwide has prominent research programmes on solar energy converting devices. Fundamental as well as applied research programmes are in progress. All these efforts of spending immense amounts of money and resources will be required in finding a suitable solution to the energy problem (Kurdgelashvili, 2011). Although the total number of research programmes conducted throughout the world is extremely large, the outcome with respect to the types of solar cell devices readily available for practical applications is limited. This reality is common not only to solar energy research but also to many other research areas as well. The accumulated knowledge generated by a large number of projects will be essential to develop a final product. Fundamental research on the related subject areas on the other hand plays a very important role in developing final applicable devices. For example, the revolutionary discovery of the transistor by Bardeen, Shockley and Brattain was 
the result of an effort to understand the fundamental principles of semiconductors.

Currently, Sri Lanka faces a major economic burden due to the dependence on imported energy resources and their high costs. The Government of Sri Lanka therefore envisions reaching a minimum level of $10 \%$ of the grid electricity from renewable energy resources in the very near future. Solar energy, one of the clean and free renewable energy resources abundantly available in Sri Lanka, could be a major cornerstone of the future renewable energy systems. Solar energy research has been going on in Sri Lanka for a considerable period of time. Research programmes on solar thermal and photovoltaic systems, solar energy materials and solar water splitting are the major programmes among them. A lot of emphasis has been given to the development of low cost thin film solar cell devices and the search for low cost semiconductor materials for solar energy applications. Many universities and research institutes in Sri Lanka are involved in these research programmes and most of them have been funded by the National Science Foundation (NSF) and the National Research Council (NRC). New concepts, methodologies and materials have been discovered and a large numbers of publications in peer-reviewed international journals have resulted. Although commercial products have not yet been realized from these research, the contributions made to the knowledge on the development of thin-film solar cells is very significant and well recognized. The resulted novel concepts, ideas and materials are being further investigated by many researchers throughout the world. This is a very good indication of the achievements and capabilities of solar energy research in Sri Lanka.
The investment on solar energy research in Sri Lanka is an investment for the future. The immediate results of those research will be research publications, patents and human resource development. With the extremely high cost of fossil fuels, Sri Lanka will have to heavily depend on solar energy and other renewable energy resources for its future energy needs. Apart from the abundant solar energy the availability of capable researchers and low project costs are among the other encouraging prospects of solar energy research in Sri Lanka. Unless Sri Lanka develops the technology on its own, in future, it might have to heavily depend on foreign technology to harness the available solar energy. A noteworthy aspect of low cost solar energy converting device technology and many renewable energy technologies is that they are not as sophisticated as many other advanced technologies and can be easily adapted in a country like Sri Lanka. Therefore continuation and further strengthening of research and development on solar energy in Sri Lanka will be a meaningful investment for the future.

\section{REFERENCES}

1. Boyle G. (2012). Renewable Energy Power: Power for a Sustainable Future. Oxford University Press, London, UK.

2. Hamakawa Y. (2004). Thin Film Solar cells: Next Generation Solar Cells and its Applications. SpringerVerlag, Berlin, Germany.

3. Kurdgelashvili L. (2011). A Review of Solar Energy, Market, Economic and Policies, Policy Research Working Paper 5845. Environment and Energy Team, Development Research Group, The World Bank, Washington DC, USA. Available at elibrary.worldbank.org/doi/pdf/10.1596/18139450-5845

Withana P. Siripala 